\title{
VEGFR1 PRIMES A UNIQUE COHORT OF DENTAL PULP STEM CELLS FOR VASCULOGENIC DIFFERENTIATION
}

\author{
M.T. Bergamo ${ }^{1,2}$, Z. Zhang' ${ }^{2}$, T.M. Oliveira ${ }^{1}$ and J.E. Nör ${ }^{2, *}$ \\ ${ }^{1}$ Department of Pediatric Dentistry, Orthodontics and Collective Health, Bauru School of Dentistry, \\ University of São Paulo, Bauru, SP, Brazil \\ ${ }^{2}$ Department of Cariology, Restorative Sciences and Endodontics, School of Dentistry, \\ University of Michigan, Ann Arbor, MI, USA
}

\begin{abstract}
Dental pulp stem cells (DPSCs) constitute a unique group of cells endowed with multipotency, self-renewal, and capacity to regenerate the dental pulp tissue. While much has been learned about these cells in recent years, it is still unclear if each DPSC is multipotent or if unique sub-populations of DPSCs are "primed" to undergo specific differentiation paths. The purpose of the present study was to define whether a subpopulation of DPSCs was uniquely primed to undergo vasculogenic differentiation.

Permanent-tooth DPSCs or stem cells from human exfoliated deciduous teeth (SHED) were flow-sorted for vascular endothelial growth factor receptor 1 (VEGFR1) and exposed to vasculogenic differentiation medium, i.e., Microvascular Endothelial Cell Growth Medium-2 BulletKit ${ }^{\mathrm{TM}}$ supplemented with $50 \mathrm{ng} / \mathrm{mL}$ rhVEGF in the presence of 0 or $25 \mu \mathrm{g} / \mathrm{mL}$ anti-human VEGF antibody (bevacizumab; Genentech). In addition, sorted SHED (i.e., VEGFR $1^{\text {high }}$ or VEGFR $1^{\text {low }}$ ) were seeded in biodegradable scaffolds and transplanted into the subcutaneous space of immunodeficient mice. Despite proliferating at a similar rate, VEGFR $1^{\text {high }}$ generated more in vitro sprouts than VEGFR $1^{\text {low }}$ cells $(p<0.05)$. Blockade of VEGF signaling with bevacizumab inhibited VEGFR $1^{\text {high }}$-derived sprouts, demonstrating specificity of responses. Similarly, VEGFR $1^{\text {high }}$ SHED generated more blood vessels when transplanted into murine hosts than VEGFR $1^{\text {low }}$ cells $(p<0.05)$. Collectively, these data demonstrated that DPSCs contain a unique sub-population of cells defined by high VEGFR1 expression that are primed to differentiate into vascular endothelial cells. These data raise the possibility of purifying stem cells with high vasculogenic potential for regeneration of vascularized tissues or for vascular engineering in the treatment of ischemic conditions.
\end{abstract}

Keywords: Stem cells, differentiation, angiogenesis, vasculogenesis, pulp biology, multipotency, tissue regeneration, vascular endothelial growth factor, endodontics.

*Address for correspondence: J.E. Nör, PhD, Department of Cariology, Restorative Sciences and Endodontics, University of Michigan School of Dentistry, 1011 N. University Rm. G049, Ann Arbor, MI 48109-1078, USA. Telephone number: +1 7349369300 Email: jenor@umich.edu

Copyright policy: This article is distributed in accordance with Creative Commons Attribution Licence (http://creativecommons.org/licenses/by-sa/4.0/).

\begin{tabular}{|c|c|c|c|}
\hline & List of Abbreviations & GAPDH & $\begin{array}{l}\text { glyceraldehyde 3-phosphate } \\
\text { dehydrogenase }\end{array}$ \\
\hline$\alpha$-MEM & $\alpha$-minimal essential medium & HDMEC & human dermal microvascular \\
\hline BMP & bone morphogenetic protein & & endothelial cell \\
\hline CD & cluster of differentiation & MEK1 & dual specificity mitogen-activated \\
\hline DAPI & 4',6-diamidino-2-phenylindole & & protein kinase kinase 1 \\
\hline DPSC & dental pulp stem cell & PE & phycoerythrin \\
\hline EGM2-MV & Microvascular Endothelial Cell & PLLA & poly-L-lactic acid \\
\hline ERG & $\begin{array}{l}\text { Growth Medium-2 BulletKit }{ }^{\mathrm{TM}} \\
\text { erythroblast transformation-specific- } \\
\text { related gene }\end{array}$ & $\begin{array}{l}\text { rh } \\
\text { SCF } \\
\text { SD }\end{array}$ & $\begin{array}{l}\text { recombinant human } \\
\text { stem cell factor } \\
\text { standard deviation }\end{array}$ \\
\hline $\begin{array}{l}\text { ERK } \\
\text { FACS }\end{array}$ & $\begin{array}{l}\text { extracellular-signal-regulated kinase } \\
\text { fluorescence-activated cell sorting }\end{array}$ & SHED & $\begin{array}{l}\text { stem cells from exfoliated deciduous } \\
\text { teeth }\end{array}$ \\
\hline FBS & fetal bovine serum & SMA & smooth muscle actin \\
\hline
\end{tabular}


SRB

STAT3

TBST

VEGF

VEGFR sulforhodamine B

signal transducer and activator of transcription 3

Tris-buffered saline with Tween 20 vascular endothelial growth factor VEGF receptor

\section{Introduction}

Dental pulp tissue regeneration requires the odontogenic and vasculogenic differentiation of resident stem cells (Sakai et al., 2010). These differentiation pathways are engaged by DPSCs in several clinical scenarios, such as direct pulp capping or pulpotomy (Casagrande et al., 2011; Fitzgerald et al., 1990). Interestingly, similar responses are also observed when DPSCs from permanent teeth (Gronthos et al., 2000) or SHED (Miura et al., 2003) are transplanted into empty root canals in an attempt to engineer new dental pulp tissue (Casagrande et al., 2010; Cordeiro et al., 2008; Rosa et al., 2013; Smith et al., 2016). While it has been clearly demonstrated that pulp stem cells differentiate into functional odontoblasts and vasculogenic endothelial cells (Sakai et al., 2010; Xu et al., 2019) that regenerate pulp-like tissues (Gan et al., 2020; Piva et al., 2017; Rosa et al., 2013), mechanisms underlying fate decisions of DPSCs remain elusive. Deep mechanistic understanding of stem cell fate decisions will allow for temporal and spatial control of differentiation events, which may further improve the success of ongoing clinical trials aiming at the engineering of dental pulp for treatment of necrotic teeth (Nakashima et al., 2017; Xuan et al., 2018).

The phenotypic hallmarks of physiological tissuespecific stem cells are self-renewal and multipotency. Recent studies have shown that the presence of pulp stem cells in the perivascular niche (Oh and Nör, 2015) enables their crosstalk with vascular endothelial cells (mediated by SCF), which is critical for maintaining stem cell self-renewal (Cucco et al., 2020; Oh et al., 2020). It has been postulated that this process of self-renewal enables the maintenance of a population of undifferentiated (stem) cells that aid pulp regeneration throughout the life of the dentin-pulp complex (Cucco et al., 2020). The multipotency of stem cells from the dental pulp has been demonstrated unequivocally by their ability to differentiate into several cell types, including odontoblasts, osteoblasts, adipocytes, neural cells, chondrocytes, and endothelial cells (Bento et al., 2013; Cordeiro et al., 2008; D'Alimonte et al., 2011; Gronthos et al., 2000; Lambrichts et al., 2017; Miura et al., 2003; Monache et al., 2019; Sakai et al., 2010; Smith et al., 2016; Yusof et al., 2018).

VEGF is a major regulator of angiogenesis and vasculogenesis during development, maintenance of health, and disease (Apte et al., 2019). VEGF induces differentiation of pulp stem cells into vascular endothelial cells via VEGFR1 signaling (Bento et al., 2013; Gorin et al., 2016; Sakai et al., 2010; Zhang et al., 2016) and anastomosis of these stemcell-derived blood vessels with the host vasculature through VE-cadherin (Sasaki et al., 2020). 3 to $5 \mathrm{~d}$ after induction with VEGF, DPSCs acquire VEGFR2 expression (Sasaki et al., 2020), which then drives vessel maturation and functional angiogenesis (Janebodin et al., 2013; Monache et al., 2019; Xu et al., 2019). These pulp stem cells are considered to be good candidates for bone tissue engineering, as they are able to differentiate into both vasculogenic endothelial cells and bone-forming osteoblasts when implanted in environments conducive to bone formation (D'Aquino et al., 2007; D'Aquino et al., 2009; Giuliani et al., 2013; Paino et al., 2017; Yusof et al., 2018). Interestingly, VEGF can be produced by osteoblasts in response to BMPs through processes that couple angiogenesis to bone formation (Deckers et al., 2002; Wang et al., 1997).

VEGF signals through VEGFR1 to activate MEK1/ ERK signaling, inhibit STAT3 transcriptional activity, and enable endothelial differentiation of pulp stem cells (Bento et al., 2013). However, it is not known whether all pulp stem cells express VEGFR1 and are capable of endothelial differentiation, or if only a subpopulation of pulp stem cells express VEGFR1 and, therefore, are "primed" for vasculogenic differentiation. The present study unveiled a sub-population of VEGFR1-expressing pulp stem cells that was primed to undergo vasculogenic differentiation and began to define the heterogeneous nature of these tissue-specific stem cells.

\section{Materials and Methods}

\section{Cell culture}

DPSCs (Lonza) and SHED (kindly provided by Songtao Shi) were cultured at $37^{\circ} \mathrm{C}$ and $5 \% \mathrm{CO}_{2}$ in $\alpha$-MEM (Invitrogen) supplemented with $20 \%$ FBS (Thermo Fisher Scientific), $1 \%$ antimycotic and antibiotic solution (Gibco). Primary HDMECs (Lonza) were cultured in EGM2-MV (Lonza). To induce vasculogenic differentiation, SHED or DPSCs were exposed to EGM2-MV supplemented with $50 \mathrm{ng} /$ mL rhVEGF ${ }_{165}$ (\#293-VE, R\&D Systems). In selected experiments, cells were exposed to 0 or $25 \mu \mathrm{g} / \mathrm{mL}$ anti-VEGF antibody, i.e., bevacizumab (\#NDC 50242060-01, Genentech, San Francisco, CA, USA).

\section{Semi-quantitative RT-PCR}

Total RNA from SHED or DPSCs was isolated using TRizol (Invitrogen), quantified by NanoDrop (Thermo Fisher Scientific), and reverse-transcribed into DNA using the Superscript II Reverse Transcriptase (Invitrogen), according to the manufacturer's instructions. The sequence of the PCR primers can be found in Table 1. 
Table 1. PCR primers. Sense = forward; antisense $=$ reverse .

\begin{tabular}{|c|c|c|}
\hline Gene & & Sequence \\
\hline \multirow{2}{*}{ VEGFR-1 } & sense & 5'-actcccttgaacacgagagttc-3' \\
\hline & antisense & 5'-gatttctcagtcgcaggtaacc-3' \\
\hline \multirow{2}{*}{ VEGFR-2 } & sense & $5^{\prime}$-gctgtctcagtgacaaaccat-3' \\
\hline & antisense & 5'-ctcccacatggattggcagagg-3' \\
\hline \multirow{2}{*}{ Tie-2 } & sense & $5^{\prime}$ tacacctgcctcatgctcag-3' \\
\hline & antisense & 5'-gcagagacatccttggaagc-3' \\
\hline \multirow{2}{*}{ CD31 } & sense & $5^{\prime}$-tactcagtcatggccatggt-3' \\
\hline & antisense & 5'-ttggccttggctttcctcag-3' \\
\hline \multirow{2}{*}{ VE-cadherin } & sense & $5^{\prime}$-cctggtataacctgactgtg-3' \\
\hline & antisense & 5'-tgtgatggtgaggatgcaga-3' \\
\hline \multirow{2}{*}{ GAPDH } & sense & 5'-gaccccttcattgacctcaact-3' \\
\hline & antisense & $5^{\prime}$-caccaccttcttgatgtcatc-3' \\
\hline
\end{tabular}

\section{Cell sorting by flow cytometry}

Cells were harvested into FACS tubes (Corning) at a density of $10^{6}$ cells/tube, washed with PBS, and incubated in the dark at room temperature for 35 min with $14 \mu \mathrm{L}$ of anti-human VEGFR1 antibody (PE-conjugated; \#FAB321P, R\&D Systems). Then, cells were washed in PBS and resuspended in Stain Buffer (\#554656, BD Bioscience). Cells were sorted according to VEGFR-1 expression levels (VEGFR $1^{\text {high }}$ or VEGFR $1^{\text {low }}$ ). As negative controls, untreated cells or cells exposed to isotype-matched non-specific IgG antibody (\#IC002P, R\&D Systems) were used. The analysis of the data was performed using the FlowJo software (Ashland, OR, USA).

\section{SRB assay}

Sorted VEGFR $1^{\text {high }}$ and VEGFR $1^{\text {low }}$ cells were seeded at the density $2.5 \times 10^{3}$ cell/well in 96-well plates. After 24-72 h, cells were fixed for $1 \mathrm{~h}$ at $4{ }^{\circ} \mathrm{C}$ using $10 \%$ trichloroacetic acid. Then, cells were washed, dried, stained using $0.4 \%$ SRB (\#S1307, Thermo Fisher Scientific), and incubated at room temperature for $30 \mathrm{~min}$. To remove the unbound excess dye, cells were washed in $1 \%$ acetic acid, allowed to dry, and then the dye was solubilized using Trizma ${ }^{\circledR}$-base (Fisher BioReagents). Plates were read at $565 \mathrm{~nm}$ using a microplate reader (GENios; Tecan, Männedorf, Switzerland). Data were obtained from 8 wells per condition and time point. Here, and throughout the manuscript, experiments were performed 3 independent times to verify the reproducibility of the data.

\section{Immunofluorescence assay}

For immunofluorescence, $5 \times 10^{4}$ cells were cultured in Nunc Lab-Tek chamber slides (Millipore) for $24 \mathrm{~h}$. Cells were washed and incubated overnight with rabbit anti-human VEGFR1 polyclonal antibody (Santa Cruz Biotechnology). Next day, excess primary antibody was washed and goat anti-rabbit antibody conjugated to Alexa Fluor 488 (1:100, Life Technologies) was used to visualize VEGFR1. Nuclei were stained using Vectashield Mounting Medium containing DAPI (Vector Laboratories).

\section{Western blot}

DPSCs or SHED were lysed in NP-40 and protein concentration was quantified at $595 \mathrm{~nm}$ (GENios). Protein lysates underwent electrophoresis and transferred to nitrocellulose membranes that were blocked in $5 \%$ non-fat dry milk for $30 \mathrm{~min}$. Membranes were exposed overnight at $4{ }^{\circ} \mathrm{C}$ to the following primary antibodies: anti-human VEGFR-1, VEGFR-2, Tie-2, CD31, VE-cadherin (Santa Cruz Biotechnology) or GAPDH (Milipore) in the following dilutions $1: 1,000,1: 1,000,1: 1,000,1: 3,000,1: 3,000$, $1: 4 \times 10^{7}$, respectively. Next day, membranes were washed $2 \times$ in TBST, incubated with appropriate secondary antibodies for $2 \mathrm{~h}$, washed again, and exposed to SuperSignal West Pico chemiluminescent substrate (\#34578, Thermo Fisher Scientific).

\section{In vitro vasculogenic differentiation assay}

$2 \times 10^{5}$ cells flow sorted as VEGFR $1^{\text {high }}$ or VEGFR $1^{\text {low }}$ were plated on standard tissue culture plates and cultured in $\alpha$-MEM supplemented with $20 \%$ FBS. Next day, vasculogenic differentiation medium (EGM2-MV supplemented with $50 \mathrm{ng} / \mathrm{mL} \mathrm{rhVEGF}_{165}$ ) was added for up to $9 \mathrm{~d}$. To confirm the endothelial differentiation of the DPSCs, Western blots were performed for VEGFR2, CD-31, VE-cadherin, and Tie-2 (Bento et al., 2013; Sasaki et al., 2020).

\section{In vitro capillary sprouting assay}

After sorting for VEGFR1, $10^{4}$ cells/well were seeded in 12-well plates pre-coated with Growth Factor Reduced Matrigel (BD) and cultured for up to $11 \mathrm{~d}$ in vasculogenic differentiation medium (i.e., EGM2MV supplemented with $50 \mathrm{ng} / \mathrm{mL}^{\mathrm{rhVEGF}}{ }_{165}$ ) in the presence of 0 or $25 \mu \mathrm{g} / \mathrm{mL}$ anti-human VEGF antibody (bevacizumab; Genentech). Capillary sprouts were counted using a light microscope at 100× magnification in 12 random fields per well in 3 independent wells per experimental condition. 
In vivo vasculogenic differentiation assay

Biodegradable, highly porous PLLA scaffolds were prepared and cut in $6 \times 6 \times 1 \mathrm{~mm}$, as described by Nör et al. (2001). SHED $\left(6 \times 10^{5}\right.$ cells/scaffold $)$ flow sorted for VEGFR1 were mixed with Matrigel, seeded in the scaffolds $(n=6)$, and transplanted into the subcutaneous space of the dorsum of severe combined immunodeficient mice (CB-17 SCID; Jackson Laboratory). After $28 \mathrm{~d}$, scaffolds were retrieved and fixed for $24 \mathrm{~h}$ at $4{ }^{\circ} \mathrm{C}$ in $10 \%$ formaldehyde. Histological sections (5 $\mu \mathrm{m}$-thick) were stained with hematoxylin-eosin or kept unstained for immunohistochemistry assay. Tissue sections were dewaxed and antigen retrieval was performed using $1 \mathrm{mg} / \mathrm{mL}$ trypsin (Merck) for $1 \mathrm{~h}$ at $37^{\circ} \mathrm{C}$. After incubation in $0.1 \%$ Triton-X-100 and $3 \% \mathrm{H}_{2} \mathrm{O}_{2}$ and background Sniper (\#BS966, Biocare Medical, Pacheco, CA, USA) for $20 \mathrm{~min}$ at room temperature, tissue sections were incubated in 1 : 100 rabbit anti-human CD31 (\#IHC-00055, Bethyl Laboratories, Montgomery, TX, USA) or rabbit antiFactor VIII (Ab-1; Thermo Fisher Scientific). Next day, unbound primary antibodies were washed away using Wash Buffer (\#S3006, Dako) and MACH3 Rabbit/Mouse Probe (\#M3M530, Biocare Medical), MACH 3 Rabbit/Mouse HRP-Polymer (\#M3R531, Biocare Medical), and Betazoid DAB Chromogen Kit (\#BDB2004, Biocare Medical) were added to the tissue sections for $20 \mathrm{~min}$ each, except for the DAB incubation that was performed for 1-2 $\mathrm{min}$. After the a

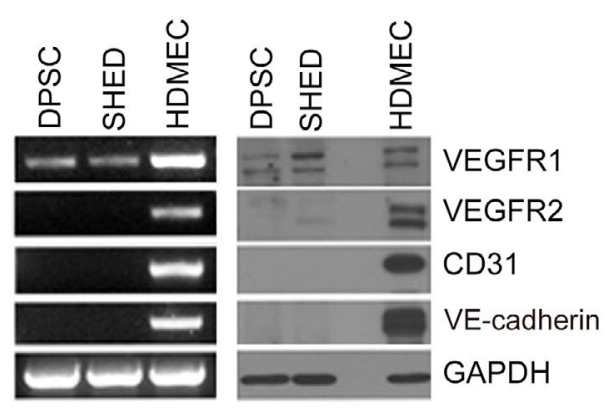

C

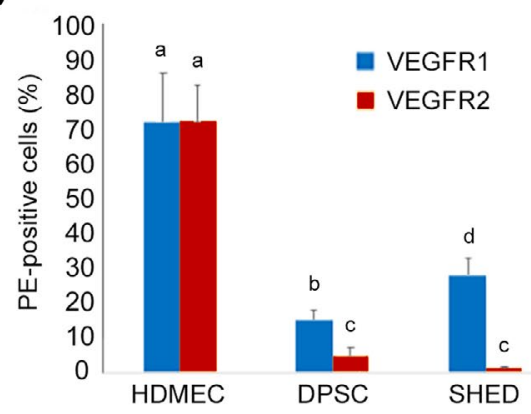

b
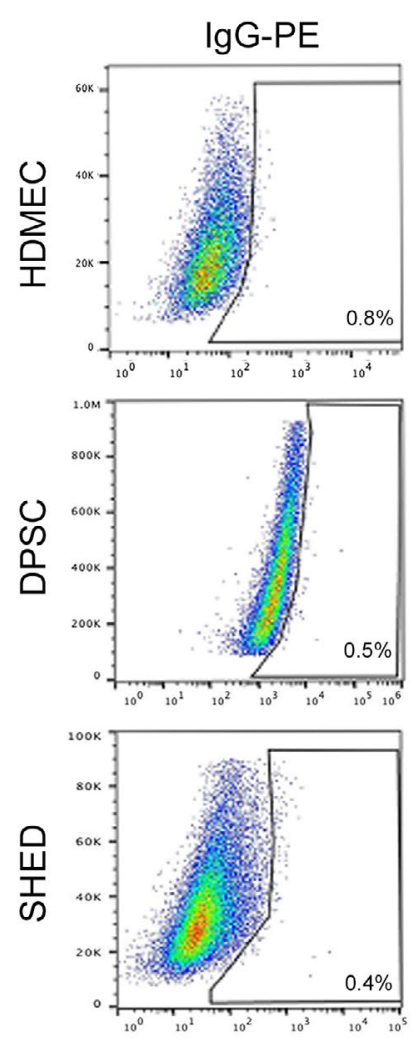

VEGFR1-PE
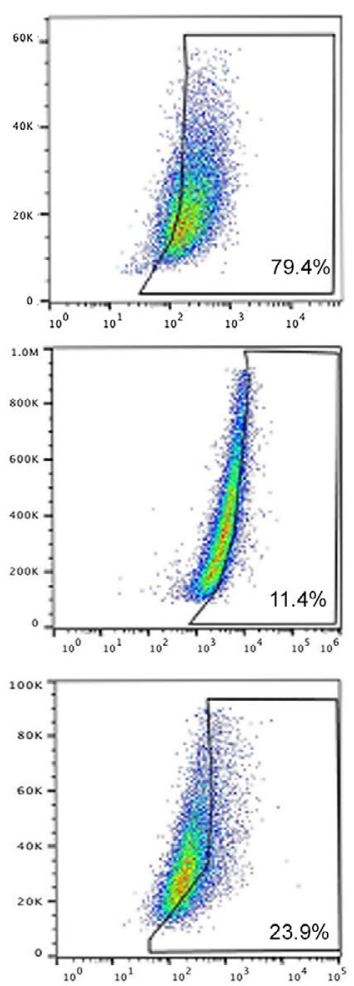
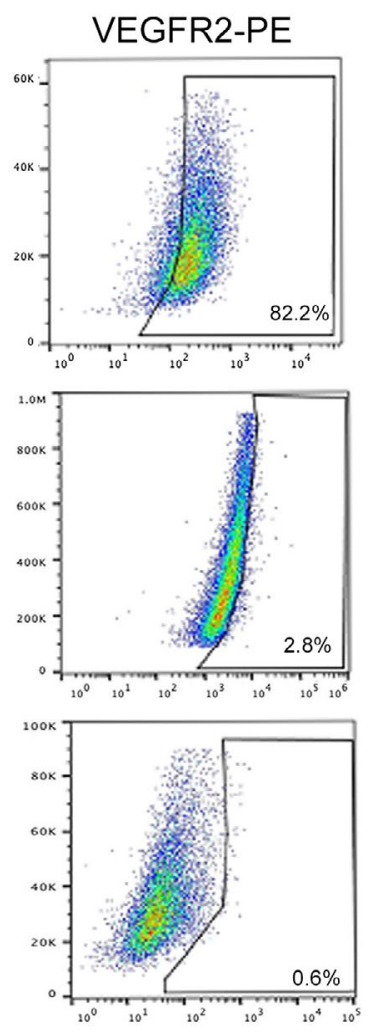

Fig. 1. Baseline expression of VEGFR1 and VEGFR2 in DPSCs. (a) RT-PCR and Western blot analyses of VEGFR1, VEGFR2, CD-31, and VE-cadherin expression in DPSCs and SHED cultured in $\alpha$-MEM $+20 \%$ FBS. (b) Flow cytometric analyses of VEGFR1 and VEGFR2 expression in SHED, DPSCs and HDMECs. Cells are presented in a dot plot of side scatter area (SSC-A) gating against PE fluorescence. Cells were analyzed using anti-VEGFR1 and anti-VEGFR2 PE-conjugated antibodies, and an isotype-matched IgG as a control to set the gating. (c) Graph depicting the percentage of VEGFR1 and VEGFR2-positive cells in SHED, DPSCs and HDMECs. Different low-case letters indicate statistical significance at $p<0.05$. 
a
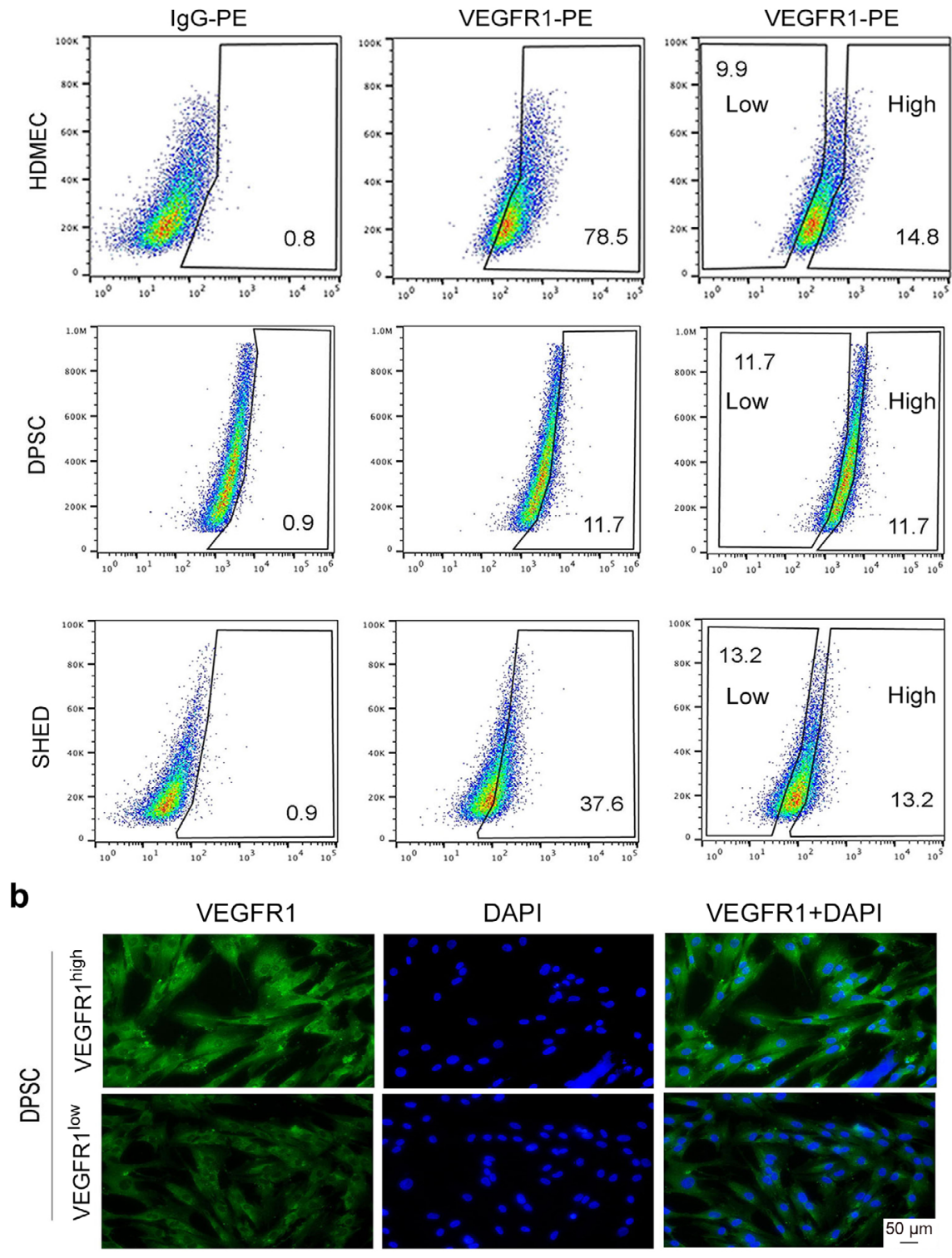

C
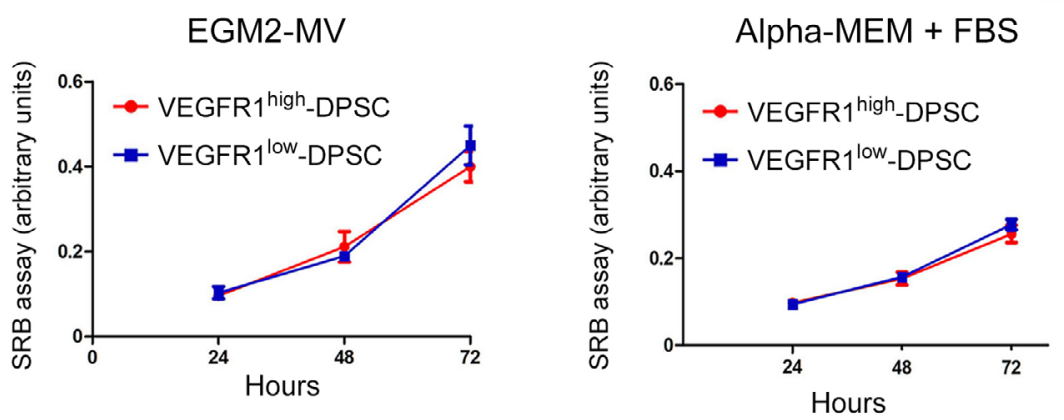

Fig. 2. VEGFR1 did not regulate proliferation of pulp stem cells. (a) Flow sorting of HDMECs, SHED, and DPSCs according to VEGFR1 expression levels (i.e., high and low), using isotype-matched IgG to set the gates. For DPSCs and SHED, equivalent percentages of VEGFR1 ${ }^{\text {high }}$ and VEGFR1 ${ }^{\text {low }}$ cells were sorted out. (b) Fluorescence microscopy images of VEGFR1 ${ }^{\text {high }}$ and VEGFR1 ${ }^{\text {low }}$ cells. Green depicts VEGFR1 expression while blue depicts DAPI nuclear staining. Scale bar: $50 \mu \mathrm{m}$. (c) Line graph depicting cell proliferation over time for VEGFR $1^{\text {high }}$ and VEGFR $1^{\text {low }}$ cells, as determined by the SRB assay. Cells were cultured in vasculogenic differentiation medium (EGM2-MV + $50 \mathrm{ng} / \mathrm{mL} \mathrm{rhVEGF}_{165}$ ) or $\alpha-\mathrm{MEM}+20 \%$ FBS for $24-72 \mathrm{~h}$. Data represents average \pm SD in 8 wells per condition. 
final wash, VectaMount (Vector Laboratories) was added for cover slip placement. Human microvessels (CD31-positive) were counted using the Image J software (NIH) in 8 random fields $(200 \times)$ by a researcher blinded to the experimental conditions. The animal work was performed under a protocol (PRO00009087) approved by the University of Michigan Animal Ethics Committee.

\section{Statistical analysis}

Statistical analyses were performed using GraphPad Prism software. Shapiro-Wilk normality test was applied in the quantitative measurements. Data were

a


Vasculogenic differentiation medium (EGM2-MV + 50 ng/mL VEGF)

C

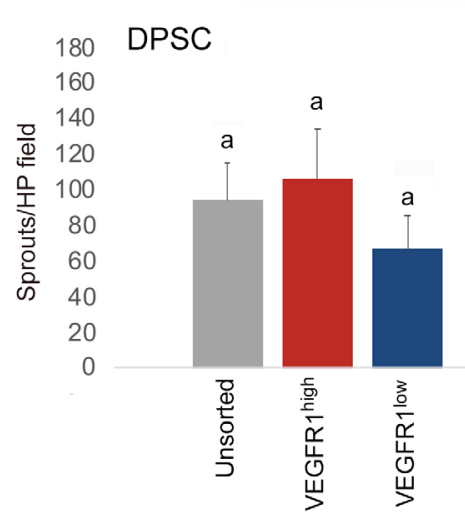

analyzed by $t$-test or one-way ANOVA followed by Tukey post-hoc test. The significance was set at $p<0.05$.

\section{Results}

\section{Baseline expression of VEGFR1 and VEGFR2 in DPSCs}

To evaluate the baseline expression level of key mediators of vasculogenesis in pulp stem cells, RT-PCR (mRNA) and Western blots (protein) of untreated DPSCs and SHED were performed, and

b
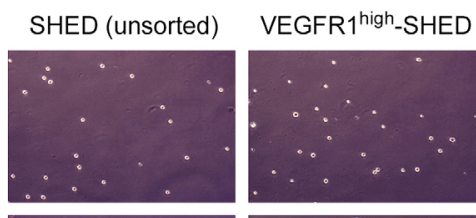

VEGFR $1^{\text {low }}-$ SHED


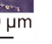

d

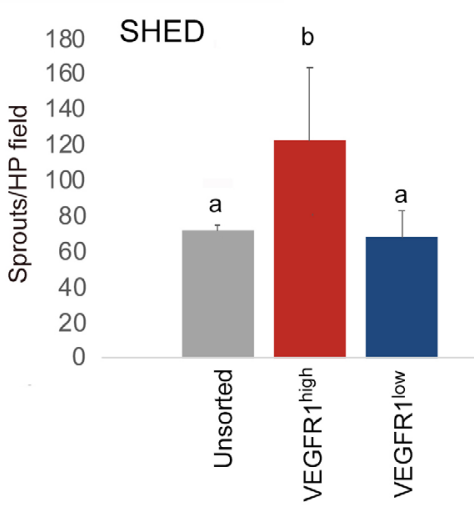

Fig. 3. VEGFR $1^{\text {high }}$ pulp stem cells generate more capillary sprouts than VEGFR $1^{\text {low }}$ cells in vitro. Cells were sorted for VEGFR1 expression levels and plated on plates coated with growth-factor-reduced Matrigel. (a,b) Representative photomicrographs (scale bar: $100 \mu \mathrm{m}$ ) of capillary sprouts generated by VEGFR $1^{\text {high }}$, VEGFR1 $1^{\text {low }}$, or unsorted DPSCs and SHED cultured in vasculogenic differentiation medium for up to $11 \mathrm{~d}$. (c,d) Bar graphs showing the number of capillary-like sprouts at the end of the experimental period (i.e., $11 \mathrm{~d}$ ). Different low case letters indicate statistical significance at $p<0.05$. Number of capillary sprouts (average $\pm \mathrm{SD}$ ) is representative of 12 random microscopic fields from triplicate wells per condition. 
primary human endothelial cells (HDMECs) were used as controls. While endothelial cells expressed all the markers evaluated (i.e., VEGFR1, VEGFR2, CD31 and VE-cadherin), SHED and DPSCs only expressed VEGFR1 at baseline (Fig. 1a). An intrinsic limitation of both RT-PCR and Western blots is the fact that cells are pooled together, which does not allow for the understanding of expression levels of specific markers in individual cells. To overcome this limitation, cells were analyzed by flow cytometry for VEGFR1 or VEGFR2 (Fig. 1b,c). Approximately $10 \%$ and $20 \%$ of DPSCs and SHED expressed VEGFR1, respectively. In contrast, only a negligeable percentage of DPSCs and SHED expressed VEGFR2. These data were consistent with the results obtained in the RT-PCR and Western blots and suggested that VEGFR1 (not VEGFR2) was the receptor engaged by VEGF to induce the vasculogenic differentiation of pulp stem cells.

\section{b}

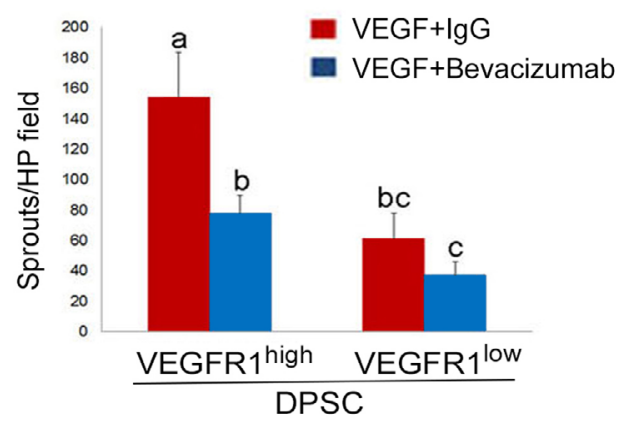

C

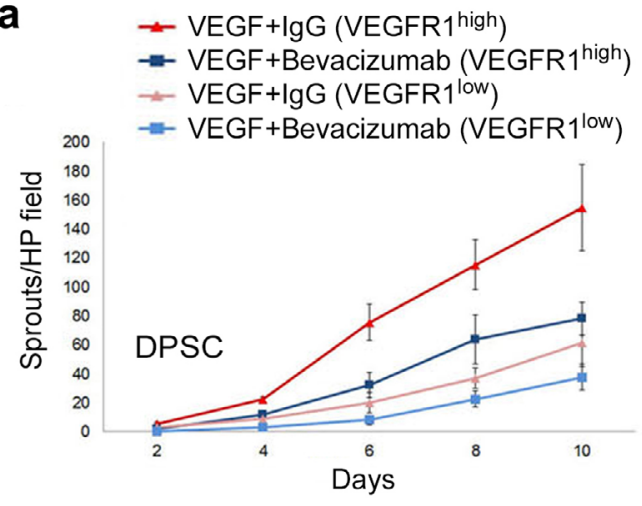

d

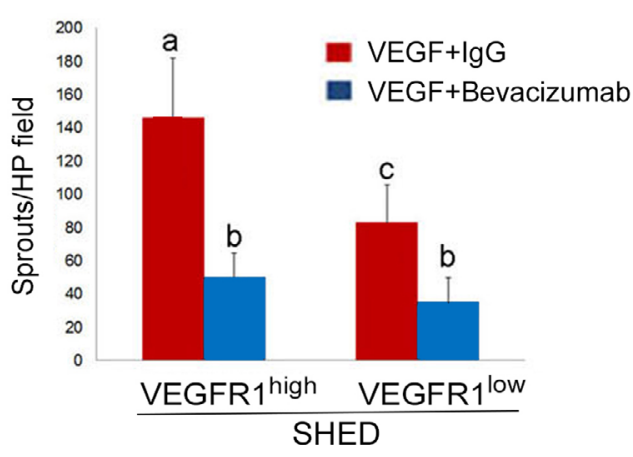

e

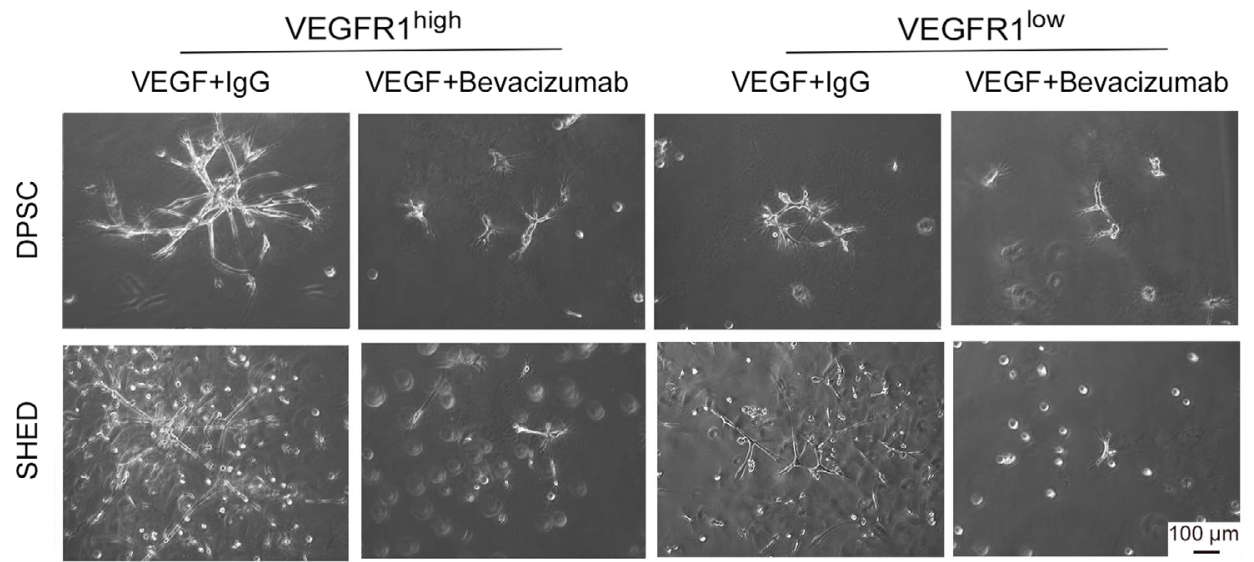

Fig. 4. VEGF blockade inhibited the vasculogenic potential of VEGFR1 ${ }^{\text {high }}$ cells in vitro. (a,c) Line graphs depicting the number of sprouts per high power field generated by DPSCs or SHED. (b,d) Bar graphs showing the number of capillary-like sprouts at the end of the experimental period (i.e., $10 \mathrm{~d}$ ). VEGFR $1^{\text {high }}$ and VEGFR1 ${ }^{\text {low }}$ DPSCs or SHED were cultured in wells pre-coated with growth-factor-reduced Matrigel and stimulated with vasculogenic differentiation medium in the presence of 0 or $25 \mu \mathrm{g} / \mathrm{mL}$ bevacizumab (anti-VEGF antibody). Different low case letters indicate statistical significance at $p<0.05$. Number of capillary sprouts (average $\pm \mathrm{SD}$ ) is representative of 12 random microscopic fields from triplicate wells per condition. (e) Representative photomicrographs of the capillary sprouts observed after $10 \mathrm{~d}$ under the experimental conditions described above (scale bar: $100 \mu \mathrm{m}$ ). 


\section{VEGFR1 did not regulate proliferation of pulp stem cells}

To examine the impact of VEGFR1 expression levels on proliferation rate, flow sorting was used to generate a subpopulation of VEGFR ${ }^{\text {high }}$ pulp stem cells and a subpopulation of VEGFR $1^{\text {low }}$ pulp stem cells (Fig. 2a). Immunofluorescence analysis showed that both populations, VEGFR $1^{\text {high }}$ and VEGFR $1^{\text {low }}$ cells, exhibited a homogeneous distribution of
VEGFR1 expression (Fig. 2b). Interestingly, the level of VEGFR1 expression (i.e., high or low) had no impact on cell density (surrogate for net effect of treatment on cell proliferation and cell survival), when DPSCs were cultured in either basal culture medium (i.e., $\alpha$-MEM + FBS) or vasculogenic differentiation medium (i.e., EGM2-MV + $50 \mathrm{ng} / \mathrm{mL}$ rhVEGF $_{165}$ ) (Fig. 2c).

a
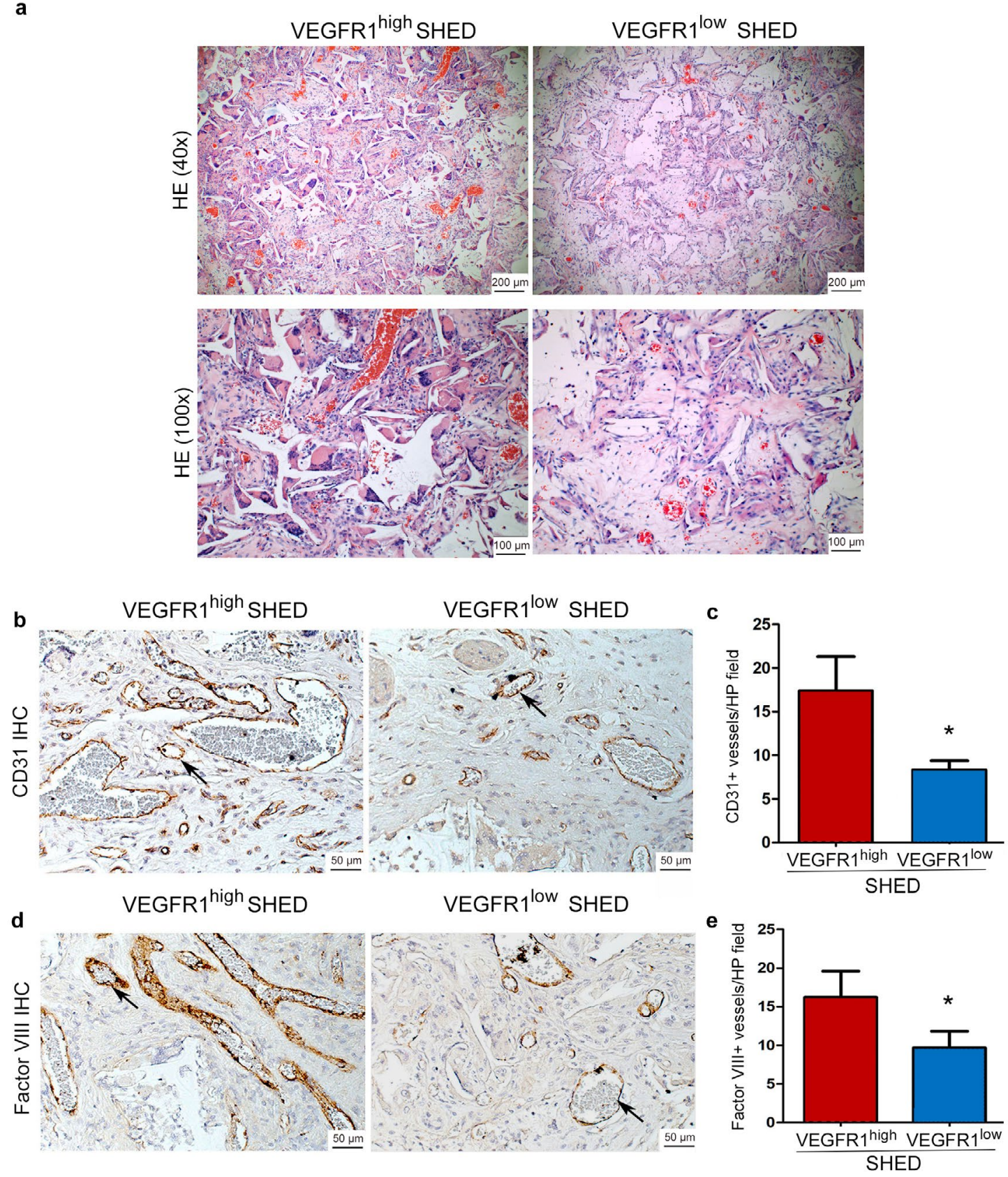

Fig. 5. VEGFR1 $1^{\text {high }}$ SHED were more vasculogenic than VEGFR1 ${ }^{\text {low }}$ SHED in vivo. (a,c) Human VEGFR1 high and VEGFR1 $1^{\text {low }}$ SHED were seeded in biodegradable scaffolds ( $n=6$ per experimental condition) and transplanted into the subcutaneous space of immunodeficient mice. 4 weeks after transplantation, the scaffolds were retrieved, fixed, and paraffin-wax embedded. (a) Representative images of sections stained with hematoxylin and eosin at low and high magnification (scale bar: $100 \mu \mathrm{m}$ or $200 \mu \mathrm{m}$ ). (b,d) Immunohistochemistry using anti-human CD-31 or anti-Factor VIII antibody to identify blood vessels (brown color). Representative vessels are indicated with black arrows (bar: $50 \mu \mathrm{m})$. (c,e) Graphs depicting the number of CD31-positive or Factor VIII-positive blood vessels inside the scaffolds. Data represent analysis of 8 randomly selected microscopic fields from each scaffold $(n=6)$ at $200 \times$. 
VEGFR1 ${ }^{\text {high }}$ pulp stem cells were more vasculogenic than VEGFR1 $1^{\text {low }}$ cells in vitro

To begin evaluating the impact of VEGFR1 expression on the vasculogenic potential of DPSCs, DPSCs and SHED were sorted for VEGFR1 levels, plated on Matrigel-coated wells, and exposed to vasculogenic differentiation medium for $11 \mathrm{~d}$. Images (representative of 3 independent experiments) showed that VEGFR1 ${ }^{\text {high }}$ SHED were more vasculogenic than VEGFR1 ${ }^{\text {low }}$ SHED (Fig. 3). A similar trend was observed when DPSCs were analyzed under similar experimental conditions (Fig. 3). To verify the specificity of these results, an independent set of studies in which sorted SHED and DPSCs were exposed to vasculogenic differentiation medium in the presence (or not) of an anti-VEGF antibody (bevacizumab) was performed (Walker et al., 2012). These experiments demonstrated that VEGFR1 ${ }^{\text {high }}$ DPSCs generated more capillary sprouts than VEGFR $1^{\text {low }}$ DPSCs (Fig. 4a, b). The same trends were observed with VEGFR1 ${ }^{\text {high }}$ SHED versus VEGFR1 1ow SHED (Fig. 4c,d). Notably, blockade of VEGF with bevacizumab decreased the number of capillary sprouts generated by DPSCs and SHED (Fig. 4a-e), demonstrating that the responses observed were dependent on active VEGF signaling.

VEGFR1 ${ }^{\text {high }}$ pulp stem cells were more vasculogenic than VEGFR1 1ow cells in vivo

Considering that SHED and DPSCs presented similar results in the in vitro studies performed (cell proliferation, capillary-like sprouting, and response to therapeutic blockade of VEGF signaling with bevacizumab), a decision was made to focus on the use of SHED as model pulp stem cells for the in vivo studies. To understand the impact of
VEGFR1 expression on the vasculogenic potential of DPSCs, SHED were sorted for VEGFR1, seeded in biodegradable scaffolds, and transplanted into SCID mice (Bento et al., 2013; Nör et al., 2001; Sasaki et al., 2020). Similar to in vitro experiments, VEGFR $1^{\text {high }}$ SHED were more vasculogenic than VEGFR $1^{\text {low }}$ cells in 8 randomly selected high-power fields per scaffold $(n=6)$ (Fig. 5). Using the anti-human CD31 antibody, which is specific to human endothelial cells (Nör et al., 2001), scaffolds seeded with VEGFR $1^{\text {high }}$ SHED contained approximately twice as many blood vessels as scaffolds seeded with VEGFR1 ${ }^{\text {low }}$ SHED (Fig. 5a,b). Notably, immunohistochemistry using anti-Factor VIII antibody confirmed the results obtained with anti-CD31 (Fig. 5c,d), despite the fact that the antiFactor VIII antibody used cross-reacted with both human and mouse endothelial cells. These findings confirmed previous reports according to which transplantation of human endothelial cells or human DPSCs results in the engineering of human blood vessels in murine hosts (Bento et al., 2013; Nör et al., 2001; Sakai et al., 2010; Sasaki et al., 2020).

\section{Discussion}

DPSCs are unique stem cells developmentally derived from the neural crest (Luo et al., 2018). The two major hallmarks of physiological stemness (multipotency and self-renewal) have been extensively characterized in these pulp stem cells (Cucco et al., 2020; Gronthos et al., 2000; Lambrichts et al., 2017; Miura et al., 2003; Oh et al., 2020; Sakai et al., 2010). While it is well known that DPSCs can differentiate into multiple cell types, it is unclear whether every single stem cell is multipotent or if DPSCs are a heterogeneous

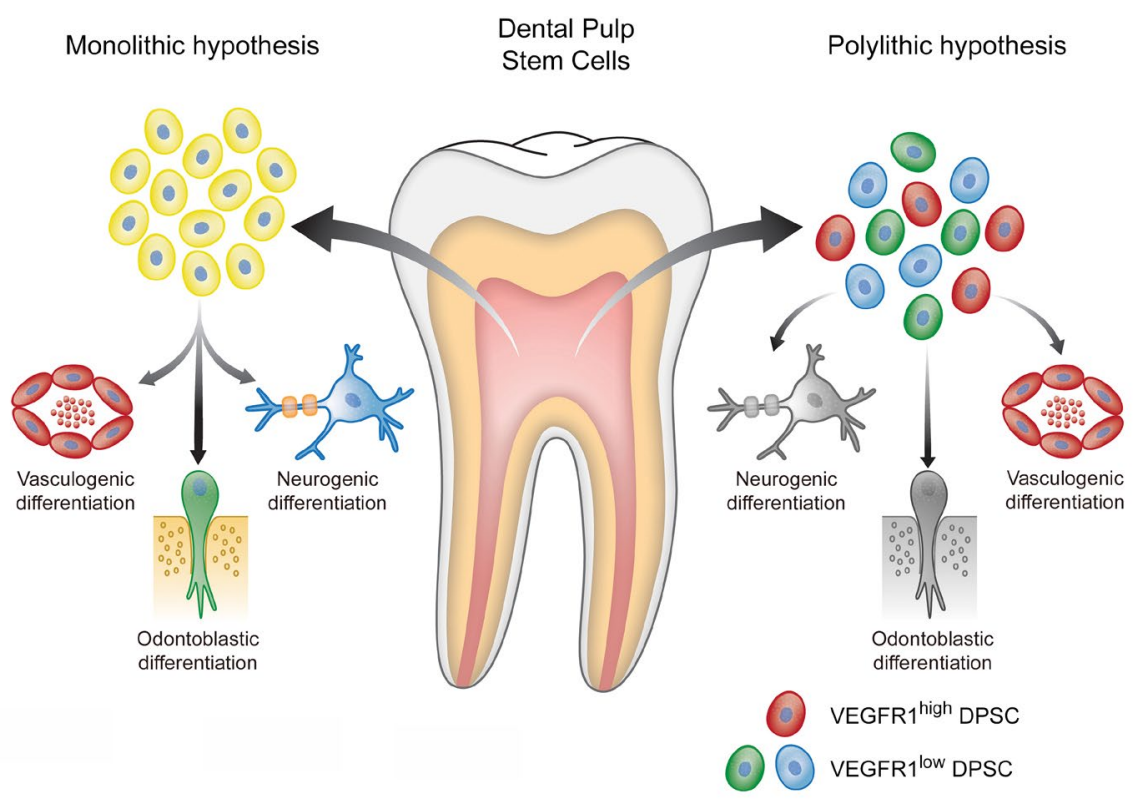

Fig. 6. Graphical diagram depicting the proposed monolithic versus polylithic hypotheses for the multipotency exhibited by DPSCs. Under the monolithic hypothesis, identical DPSCs give rise tomultiple cell types by engaging distinct differentiation pathways. In contrast, under the polylithic hypothesisDPSCs are composed of a heterogeneous mix of cells that are uniquely primed to specific cell fates. 
cell type containing smaller sub-groups of cells that are "primed" to undergo diverse differentiation pathways. The present study began to explore this question by hypothesizing that stem cells of dental pulp origin contain a subgroup of cells that are primed to undergo a vasculogenic differentiation pathway.

VEGFR1 and VEGFR2 are constitutively expressed in endothelial cells and function as the primary regulators of VEGF signaling in blood vessels (Karaman et al., 2018; Trapiella-Alfonso et al., 2018). While VEGFR1 signaling is required for the survival of vascular endothelial cells, VEGFR2 regulates blood vessel sprouting and neovascularization (Zhang et al., 2010). Interestingly, the receptor that fine tune angiogenesis and vascular remodeling is VEGFR2, but VEGF binds to VEGFR1 (soluble or membrane bound) with more affinity than to VEGFR2. In this way, the number of VEGF molecules available to bind to VEGFR2 is modulated and the angiogenic process regulated (Balsera et al., 2017; Millauer et al., 1993; Trapiella-Alfonso et al., 2018). The present study showed that DPSCs expressed VEGFR1 constitutively, but not VEGFR2. However, VEGFR2 expression can be induced upon exposure of DPSCs to vasculogenic differentiation medium containing $\mathrm{VEGF}_{165}$ (Bento et al., 2013; Sasaki et al., 2020). Also, expression of CD31 and VE-cadherin following upregulation of VEGFR2 expression is observed in DPSCs (Sasaki et al., 2020). Indeed, VEGF induces activation of MEK/ERK signaling and induction of ERG transcriptional activity, resulting in the expression of VE-cadherin (Sasaki et al., 2020). Collectively, these data suggest that VEGF binding to VEGFR1 initiated the vasculogenic differentiation of DPSCs. Once these cells begin to express VEGFR2, they acquire the capacity to become differentiated vascular endothelial cells expressing CD31 that are able to form functional vascular networks anastomizing with existing vessels through VEcadherin (Sasaki et al., 2020).

An important issue to consider is the effect of VEGF signaling through VEGFR1 on vasculogenic responses mediated by DPSCs. VEGF induces proliferation, migration, and survivals of endothelial cells, but these cells express both VEGFR1 and VEGFR2 (Apte et al., 2019; Karaman et al., 2018). However, the full impact of VEGF on DPSCs (expressing only VEGFR1 at baseline) was unclear. The results presented demonstrated that VEGFR1 levels (i.e., high or low) had no impact on DPSC proliferation when cells were exposed to vasculogenic medium (containing $50 \mathrm{ng} / \mathrm{mL}$ VEGF $_{165}$ ) or regular medium (containing trace levels of VEGF present in bovine serum). As such, the increased number of capillary sprouts observed in VEGFR $1^{\text {high }}$ cells was not simply a consequence of an increased number of cells. In vitro data also suggested that in unsorted conditions, the VEGFR $1^{\text {high }}$ population "took over" and exhibited a predominant effect on overall capillary sprouting, as the number of sprouts generated by unsorted cells was lower than that of sorted VEGFR1 ${ }^{\text {high }}$ cells (particularly with SHED).

Western blots and flow cytometric analyses demonstrated that a higher percentage of SHED exhibited high levels of VEGFR1, when compared to DPSCs. This is consistent with the observation that SHED are more angiogenic than DPSCs in response to VEGF (Xu et al., 2018), and with the results of the capillary sprout assays performed using unsorted cells. However, once the VEGFR $1^{\text {high }}$ cells were sorted out from both DPSCs and SHED, the sorted cells from both cell types generated similar numbers of capillary sprouts in vitro. As such, it is possible to conclude that the vasculogenic potential of each individual VEGFR1 $1^{\text {high }}$ SHED was similar to the vasculogenic potential of each individual VEGFR $1^{\text {high }}$ DPSC. But, in aggregate, SHED are more vasculogenic because they contain about twice as many VEGFR $1^{\text {high }}$ cells as DPSCs from permanent teeth.

For many years, researchers have worked under the assumption that DPSCs consisted of a monolithic cell population in which multipotency was a consequence of the possibility of each stem cell to differentiate into several different cell types (Fig. 6). However, a series of observations contradict this hypothesis, at least with regard to vasculogenic differentiation. Several studies have demonstrated that global (shRNA-mediated) silencing of VEGFR1 expression inhibits vasculogenic differentiation of DPSCs (Bento et al., 2013; Sakai et al., 2010). However, at that time, it was not known whether every single DPSC expressed VEGFR1, or if only a sub-population of these cells expressed VEGFR1 (and was capable of responding to VEGF stimulation). In the present study, it was observed that only 10-15\% DPSCs (permanent teeth) and 20-25\% SHED (primary teeth) expressed constitutive VEGFR1, while the remaining cells (i.e., most of these cells) did not express this receptor. This finding gave rise to the hypothesis that DPSCs are constituted of polylithic (i.e., heterogeneous) cells containing one small subpopulation of cells that are primed to respond to VEGF stimulation and undergo vasculogenic differentiation (as they express VEGFR1), while the remaining cells cannot respond to VEGF (as they do not express VEGFR1). This raises the intriguing possibility that other sub-populations of DPSCs are primed to undergo alternative differentiation pathways, such as odontoblastic or neurogenic fates (Fig. 6). Following studies aim at expanding the understanding of the polylithic hypothesis, through identification of signaling events and characterization of DPSCs that undergo non-vasculogenic differentiation pathways.

A limitation inherent to the present study design was that the stability of VEGFR1 expression levels after transplantation of the cells into murine hosts was not known. It is possible that cells that were initially sorted as VEGFR1 ${ }^{\text {high }}$ did not maintain a high VEGFR1 expression level after several weeks 
in the mouse. Similarly, VEGFR $1^{\text {low }}$ cells might not remain exhibiting low expression levels of this receptor. These expression levels cannot be accurately quantified in SHED-derived blood vessels in vivo. Notably, this perceived limitation may explain the observation that SHED-derived blood vessels were also found in scaffolds seeded with VEGFR1 ${ }^{\text {low }}$ cells, albeit in significantly lower numbers.

In conclusion, the present work demonstrated the critical role of VEGF signaling through VEGFR1 for the vasculogenic differentiation of DPSCs. Perhaps more importantly, it demonstrated that DPSCs are polylithic and contain at least one unique subset of stem cells characterized by high VEGR1 expression that are primed for vasculogenic differentiation. These results suggested the possibility of purifying specific subpopulations of pulp stem cells according to specific needs. This discovery raises the possibility of sorting for, or specifically engaging, VEGFR1 ${ }^{\text {high }}$ DPSCs for vascular engineering and treatment of ischemic conditions.

\section{Acknowledgments}

The authors thank Dr. Songtao Shi for providing the SHED used in the study. We also thank Dr. Maria A. Machado for all the support, mentorship, and guidance throughout this research project. This work was funded by grant \#RO1-DE021410 from the National Institutes of Health (N.I.H.) and grant \#2018/13675-0 from São Paulo Research Foundation (FAPESP). The authors declare no potential conflicts of interest with respect to the authorship and/or publication of this article.

\section{References}

Apte RS, Chen DS, Ferrara N (2019) VEGF in signaling and disease: beyond discovery and development. Cell 176: 1248-1264.

Balsera B, Bonache MA, Reille-Seroussi M, GageyEilstein N, Vidal M, Gonzalez-Muniz R, Perez de Vega MJ (2017) Disrupting VEGF-VEGFR1 interaction: de novo designed linear helical peptides to mimic the VEGF13-25 fragment. Molecules 22: 1846-1854.

Bento LW, Zhang Z, Imai A, Nor F, Dong Z, Shi S, Araujo FB, Nör JE (2013) Endothelial differentiation of shed requires MEK1/ERK signaling. J Dent Res 92: 51-57.

Casagrande L, Cordeiro MM, Nor SA, Nör JE (2011) Dental pulp stem cells in regenerative dentistry. Odontology 99: 1-7.

Casagrande L, Demarco FF, Zhang Z, Araujo FB, Shi S, Nor JE (2010) Dentin-derived BMP2 and odontoblast differentiation. J Dent Res 89: 603-608.

Cordeiro MM, Dong Z, Kaneko T, Zhang Z, Miyazawa M, Shi S, Smith AJ, Nör JE (2008) Dental pulp tissue engineering with stem cells from exfoliated deciduous teeth. J Endod 34: 962-969.
Cucco C, Zhang Z, Botero TM, Chiego DJ, Castilho RM, Nör JE (2020) SCF/C-Kit signaling induces selfrenewal of dental pulp stem cells. J Endod 46: S56-S62.

D'Alimonte I, Nargi E, Mastrangelo F, Falco G, Lanuti P, Marchisio M, Miscia S, Robuffo I, Capogreco M, Buccella S, Caputi S, Caciagli F, Tetè S, Ciccarelli R (2011) Vascular endothelial growth factor enhances in vitro proliferation and osteogenic differentiation of human dental pulp stem cells. J Biol Regul Homeost Agents 25: 57-69.

D'Aquino R, Graziano A, Sampaolesi M, Laino G, Pirozzi G, Rosa AD, Papaccio G (2007) Human postnatal dental pulp cells co-differentiate into osteoblasts and endotheliocytes: a pivotal synergy leading to adult bone tissue formation. Cell Death Differ 14: 1162-1171.

D'Aquino R, Rosa AD, Lanza V, Tirino V, Laino L, Graziano A, Desiderio V, Laino G, Papaccio G (2009) Human mandible bone defect repair by the grafting of dental pulp stem/progenitor cells and collagen sponge biocomplexes. Eur Cell Mater 18: 75-83.

Deckers MM, van Bezooijen RL, van der Horst G, Hoogendam J, van Der Bent C, Papapoulos SE, Löwik CW (2002) Bone morphogenetic proteins stimulate angiogenesis through osteoblast-derived vascular endothelial growth factor A. Endocrinology 143: 1545-1553.

Fitzgerald M, Chiego DJ, Heys DR (1990) Autoradiographic analysis of odontoblast replacement following pulp exposure in primate teeth. Arch Oral Biol 35: 707-715.

Gan L, Liu Y, Cui D, Pan Y, Zheng L, Wan M (2020) Dental tissue-derived human mesenchymal stem cells and their potential in therapeutic application. Stem Cells Int 2020: 1-17.

Giuliani A, Manescu A, Langer M, Rustichelli F, Desiderio V, Paino F, Rosa AD, Laino L, D'Aquino R, Tirino V, Papaccio G (2013) Three years after transplants in human mandibles, histological and in-line holotomography revealed that stem cells regenerated a compact rather than a spongy bone: biological and clinical implications. Stem Cells Transl Med 2: 316-324.

Gorin C, Rochefort GY, Bascetin R, Ying H, Lesieur J, Sadoine J, Beckouche N, Berndt S, Novais A, Lesage M, Hosten B, Vercellino L, Merlet P, Le-Denmat D, Marchiol C, Letourneur D, Nicoletti A, Vital SO, Poliard A, Salmon B, Muller L, Chaussain C, Germain $S$ (2016) Priming dental pulp stem cells with fibroblast growth factor-2 increases angiogenesis of implanted tissue-engineered constructs through hepatocyte growth factor and vascular endothelial growth factor secretion. Stem Cells Transl Med 5: 392-404.

Gronthos S, Mankani M, Brahim J, Robey PG, Shi S (2000) Postnatal human dental pulp stem cells (DPSCs) in vitro and in vivo. Proc Natl Acad Sci U S A 97: 13625-13630.

Janebodin K, Zeng Y, Buranaphatthana W, Ieronimakis N, Reyes M (2013) VEGFR2-dependent angiogenic capacity of pericyte-like dental pulp stem cells. J Dent Res 92: 524-531. 
Karaman S, Leppänen VM, Alitalo K (2018) Vascular endothelial growth factor signaling in development and disease. Development 145: dev151019. DOI: 10.1242/dev.151019.

Lambrichts I, Driesen RB, Dillen Y, Gervois P, Ratajczak J, Vangansewinkel T, Wolfs E, Bronckaers A, Hilkens P (2017) Dental pulp stem cells: their potential in reinnervation and angiogenesis by using scaffolds. J Endod 43: S12-S16.

Luo L, He Y, Wang X, Key B, Lee BH, Li H, Ye $Q$ (2018) Potential roles of dental pulp stem cells in neural regeneration and repair. Stem Cells Int 2018: 1731289. DOI: $10.1155 / 2018 / 1731289$.

Millauer B, Wizigmann-Voos S, Schnurch H, Martinez R, Moller NP, Risau W, Ullrich A (1993) High affinity vegf binding and developmental expression suggest FLK-1 as a major regulator of vasculogenesis and angiogenesis. Cell 72: 835-846.

Miura M, Gronthos S, Zhao M, Lu B, Fisher LW, Robey PG, Shi S (2003) SHED: stem cells from human exfoliated deciduous teeth. Proc Natl Acad Sci U S A 100: 5807-5812.

Monache SD, Martellucci S, Clementi L, Pulcini F, Santilli F, Mei C, Piccoli L, Angelucci A, Mattei V (2019) In vitro conditioning determines the capacity of dental pulp stem cells to function as pericyte-like cells. Stem Cells Dev 28: 695-706

Nakashima M, Iohara K, Murakami M, Nakamura H, Sato Y, Ariji Y, Matsushita K (2017) Pulp regeneration by transplantation of dental pulp stem cells in pulpitis: a pilot clinical study. Stem Cell Res Ther 8: 61. DOI: 10.1186/s13287-017-0506-5.

Nör JE, Peters MC, Christensen JB, Sutorik MM, Linn S, Khan MK, Addison CL, Mooney DJ, Polverini PJ (2001) Engineering and characterization of functional human microvessels in immunodeficient mice. Lab Invest 81: 453-463.

Oh M, Nör JE (2015) The perivascular niche and self-renewal of stem cells. Front Physiol 6: 367. DOI: 10.3389/fphys.2015.00367.

Oh M, Zhang Z, Mantesso A, Oklejas AE, Nör JE (2020) Endothelial-initiated crosstalk regulates dental pulp stem cell self-renewal. J Dent Res 99: 1102-1111.

Paino F, Noce ML, Giuliani A, Rosa AD, Mazzoni S, Laino L, Amler E, Papaccio G, Desiderio V, Tirino V (2017) Human DPSCs fabricate vascularized woven bone tissue: a new tool in bone tissue engineering. Clin Sci 131: 699-713.

Piva E, Tarle SA, Nör JE, Zou D, Hatfield E, Guinn T, Eubanks EJ, Kaigler D (2017) Dental pulp tissue regeneration using dental pulp stem cells isolated and expanded in human serum. J Endod 43: 568-574.

Rosa V, Zhang Z, Grande RH, Nör JE (2013) Dental pulp tissue engineering in full-length human root canals. J Dent Res 92: 970-975.

Sakai VT, Zhang Z, Dong Z, Neiva KG, Machado MA, Shi S, Santos CF, Nör JE (2010) SHED differentiate into functional odontoblasts and endothelium. J Dent Res 89: 791-796.

Sasaki JI, Zhang Z, Oh M, Pobocik AM, Imazato S, Shi S, Nör JE (2020) VE-cadherin and anastomosis of blood vessels formed by dental stem cells. J Dent Res 99: 437-445.

Smith AJ, Duncan HF, Diogenes A, Simon S, Cooper PR (2016) Exploiting the bioactive properties of the dentin-pulp complex in regenerative endodontics. J Endod 42: 47-56.

Trapiella-Alfonso L, Broussy S, Liu WQ, Vidal M, Lecarpentier E, Tsatsaris V, Gagey-Eilstein N (2018) Colorimetric immunoassays for the screening and specificity evaluation of molecules disturbing VEGFs/ VEGFRs interactions. Anal Biochem 544: 114-120.

Walker EJ, Su H, Shen F, Degos V, Amend G, Jun K, Young WL (2012) Bevacizumab attenuates VEGFinduced angiogenesis and vascular malformations in the adult mouse brain. Stroke 43: 1925-1930.

Wang DS, Miura M, Demura H, Sato K (1997) Anabolic effects of 1,25-dihydroxyvitamin D3 on osteoblasts are enhanced by vascular endothelial growth factor produced by osteoblasts and by growth factors produced by endothelial cells. Endocrinology 138: 2953-2962.

Xu JG, Gong T, Wang YY, Zou T, Heng BC, Yang YQ, Zhang CF (2018) Inhibition of TGF-beta signaling in shed enhances endothelial differentiation. J Dent Res 97: 218-225.

Xu M, He J, Zhang C, Xu J, Wang Y (2019) Strategies for derivation of endothelial lineages from human stem cells. Stem Cell Res Ther 10: 1-14.

Xuan K, Li B, Guo H, Sun W, Kou X, He X, Zhang Y, Sun J, Liu A, Liao L, Liu S, Liu W, Hu C, Shi S, Jin Y (2018) Deciduous autologous tooth stem cells regenerate dental pulp after implantation into injured teeth. Sci Transl Med 10: eaaf3227. DOI: 10.1126/ scitranslmed.aaf3227.

Yusof MFH, Zahari W, Hashim SNM, Osman ZF, Chandra H, Kannan TP, Noordin KBAA, Azlina A (2018) Angiogenic and osteogenic potentials of dental stem cells in bone tissue engineering. J Oral Biol Craniofac Res 8: 48-53.

Zhang Z, Neiva KG, Lingen MW, Ellis LM, Nör JE (2010) VEGF-dependent tumor angiogenesis requires inverse and reciprocal regulation of VEGFR1 and VEGFR2. Cell Death Diff 17: 499-512.

Zhang Z, Nor F, Lingen MW, Oh M, Cucco C, Shi S, Nör JE (2016) Wnt-B-catenin signaling determines the vasculogenic fate of postnatal mesenchymal stem cells. Stem Cells 34: 1576-1587.

\section{Discussion with Reviewers}

Catherine Chaussain: Can you please discuss how you envision the use of VEGFR $1^{\text {high }}$ DPSCs (or SHED) for pulp or bone engineering applications?

Authors: This issue is of critical importance in the context of translational use of stem cells of dental origin. One could conceive the use of sorted VEGFR $1^{\text {high }}$ DPSCs (or SHED) as a strategy to prevascularize constructs (grafts) that will be used as bone replacements. On the other hand, if pulp stem cells are being used as a single source of cells for 
pulp or bone tissue engineering, it is likely preferable to use the full complement of stem cells (SHED or DPSCs). Such strategy would take full advantage of the fact that these cells are endowed with the ability to differentiate in both vasculogenic endothelial cells and bone-forming cells (D'Aquino et al., 2007), or vasculogenic endothelial cells and dental pulpforming cells (Sakai et al., 2010). Notably, if the translational goal is to revascularize ischemic tissues or organs (e.g., heart, limb), then the use of VEGFR1 high SHED (or DPSCs) would likely improve results as these cells are endowed with a higher vasculogenic potential than other (i.e., VEGFR1 $1^{\text {low }}$ ) sub-populations of pulp stem cells.

Pierfrancesco Pagella: Do VEGFR $1^{\text {high }}$ and VEGFR $1^{\text {low }}$ DPSCs and SHED have the same potential to give rise to arterial and venous endothelial cells?

Authors: The present study showed that VEGFR1 ${ }^{\text {high }}$ cells constitute the primary cell source for pulpstem-cell-derived vasculogenesis. However, the experimental design did not allow for distinction between arterial or venous endothelial cell fate. Most (if not all) SHED-derived vessels were rather small and within the expected size of microvessels (capillaries). Zhang et al. (2016) reported that some DPSC-derived blood vessels undergo maturation and become invested with SMA-positive cells upon transplantation in mice. As mural investment and vessel maturation is observed in some (but not all) DPSC-derived blood vessels, it is possible that some pulp stem cells undergo arterial while others undergo venous differentiation. However, the answer to this interesting question will require a side-byside comparison of VEGFR1 $1^{\text {high }}$ and VEGFR1 $1^{\text {low }}$ DPSCs and SHED to understand differences in endothelial differentiation potential between these two subpopulations in these two cell types. We plan to pursue this study as a next step in this project and report the results in an upcoming manuscript.

Pierfrancesco Pagella: Do the authors expect that VEGFR $1^{\text {high }}$ and VEGFR1 ${ }^{\text {low }}$ DPSCs would keep this difference in VEGFR1 expression also when challenged, e.g., upon dental injury or when transplanted in an injured tissue?

Authors: Sasaki et al. (2020) have recently reported the results of a detailed time course on the impact of treatment with a vasculogenic differentiation medium containing VEGF on the expression of VEGFR1, VEGFR2 and markers of endothelial differentiation. Unstimulated pulp stem cells express VEGFR1 at baseline, but do not express VEGFR2, CD31, or VE-cadherin. Upon stimulation with the vasculogenic differentiation medium, DPSCs progressively acquire expression of VEGFR2, then CD31, and finally VE-cadherin within a period of 5-7 d. Notably, VEGFR1 expression levels remain unchanged within this time frame. Considering the limitations of this in vitro study, one could predict that VEGFR1 expression levels will also remain unchanged upon dental injury or transplantation. However, a more definitive answer to this question would require a specific in vivo study where VEGFR1 expression in stem cells of injured dental pulps is quantified by laser capture microdissection + qRTPCR, or by flow cytometry of the entire tissue using a marker for stem cells combined with anti-VEGFR1 antibody. Again, this is a very interesting question that deserves to be answered in future studies.

Editor's note: The Scientific Editor responsible for this paper was Thimios Mitsiadis. 